\title{
TEKRARLAYAN ATEŞ ATAKLARI: MIRIZZI SENDROMU OLGU SUNUMU
}

\author{
Reccurent Fever Atacks: Mirizzi Syndrome A Case Report
}

\section{Ayşegül TUNA ${ }^{1}$ (D), Canver ÖNAL ${ }^{2}$ (D), Okan ÇALIŞKAN ${ }^{1}$}

${ }^{1}$ Kars Harakani Devlet Hastanesi, Enfeksiyon Hastallklarl ve Klinik Mikrobiyoloji Bölümü, KARS, TÜRKIYYE

${ }^{2}$ Kars Harakani Devlet Hastanesi, Radyoloji Bölümü, KARS, TÜRKIYE

Mirizzi sendromu safra kesesi taşına bağlı gelişen ve nadir görülen bir komplikasyondur. Mirizzi sendromu olan hastanın abdomen cerrahisi sırasında inflame kese ve kese kanalının yaralanma riski olduğu için preoperatif tanı konulması çok önemlidir. Ancak patognomonik görüntüsü olmadığı için, modern görüntüleme tekniklerine rağmen preoperatif tanı konulması zordur. Bu nedenle çoğu zaman intraoperatif tanı koyulur. Tedavisi cerrahidir. Bu yazıda titremeyle yükselen ateş nedeniyle hastaneye başvuran 85 yaşındaki erkek hasta sunulmuştur. Tekrarlayan ateş atakları nedeniyle hastaneye yatırılan hastanın, antibiyotik kullanımı sırasında ateş yüksekliğinin gelişmesi sonucu intravenöz kontrast madde verilerek çekilen magnetik rezonans görüntüleme sonrası hastaya Mirizzi sendromu tanısı konulmuş ve hasta tedavi edilmiştir.

Anahtar Kelimeler: Mirizzi sendromu, kolesistit, kolelitiazis
Mirizzi syndrome is an unusual complication due to gallstones. Preoperative diagnosis is very important because there is a risk of injury to the inflamed gallbladder and gallbladder duct during surgical treatment of a patient with Mirizzi syndrome. However, preoperative diagnosis is difficult despite modern imaging techniques, since it does not have a pathognomonic image. For this reason, Mirizzi syndrome can often be diagnosed intraoperatively. The treatment is surgery. In this case report, an 85 -year-old male patient who was admitted to the hospital due to fever rising with chills is presented. The patient was hospitalized for recurrent episodes of fever. As a result of the development of fever during antibiotic use, magnetic resonance imaging with intravenous contrast was obtained and the patient was diagnosed with Mirizzi syndrome and treated thereafter.

Keywords: Mirizzi syndrome, cholecystitis, cholelithiasis 


\section{GİRIȘ}

Mirizzi sendromu (MS) safra kesesi taşına bağlı olarak gelişen ve nadir görülen bir komplikasyondur. Kolelityazis hastalarının \%1'inde görülür. MS safra kesesinin sistik kanalı veya infundubulumda gömülü bir taşın diştan bası ile hepatik kanal obstrüksüyonuna sebep olmasıyla gelişen klinik tablodur (1-3). Oluşan basıya bağlı olarak kesenin tamamını kaplayacak genişlikte fistül açılabilir ve fistül boyutuna göre sinıflandirılması yapılır $(4,5)$. Preoperatif tan1 konulması cerrahi sırasında inflame kese duvarı ve kese kanalının yaralanma riskini azaltır (3). T1kanma sarılığı ile karakterize klinikle takip edilen hastalara tanı modern görüntüleme tekniklerine rağmen çoğu zaman operasyon sirasinda konulmakta veya safra kesesi duvarında kronik inflamasyona sekonder gelişen düzensizlikler nedeniyle nadir de olsa safra kesesi malignitesi ile karıştırılabilmektedir $(1,6)$.

\section{OLGU SUNUMU}

Seksen beş yaşında erkek hasta titremeyle yükselen ateş şikayetiyle enfeksiyon hastalıkları ve klinik mikrobiyoloji polikliniğine başvurdu. Hastadan alınan anamnezde son iki yıldır aralıklı olarak şikayetlerinin tekrarladığı, bu şikayetlerle başvurduğu dış merkezde bir sene önce ERCP yapıldığı öğrenildi. Hastada titremeyle yükselen ateş haricinde herhangi bir semptom yoktu. Fizik muayenesinde odağa yönlendirecek herhangi bir patoloji saptanmadı. Farenks doğaldı, menenjismus bulguları yoktu, her iki hemitoraks solunuma eşit katılıyordu, batın muayenesi normaldi, defans, rebound, hassasiyet, Murphy bulgusu saptanmadi. Suprapubik hassasiyet ve kostovertebral açı hassasiyeti yoktu. Vücudunda erizipel, selülit, döküntü saptanmadi. Ele gelen servikal, axiller, inguinal lenfadenopatisi yoktu. Hastanın laboratuvar testleri bakteriyel enfeksiyon ile uyumluydu (Beyaz küre sayıs1 $27.730 \mathrm{u} / \mathrm{L}, \% 92$ nötrofil hakimiyeti mevcut, CRP: 228 mg/L, AST: 93 u/L, ALT: $71 \mathrm{u} / \mathrm{L}$, Total bilirübin: 0.97 mg/dl, Direk bilirübin: 0.38mg/dl, Üre: $103.1 \mathrm{mg} / \mathrm{dl}$, Kreatinin: $1.76 \mathrm{mg} / \mathrm{dl}$ ). Ateş etyolojisi araştırmak için istenen abdomen ultrasonografisi sonucunda safra kesesi distandü, transvers çap1 $40 \mathrm{~mm}$, kese duvar kalınlığ1 4 mm ölçüldü. Kesede kolestirol kristali ve safra çamuru izlendi. Hastanın çekilen toraks bilgisayarlı tomografi sonucunda akciğerde patoloji saptanmamakla birlikte görüntüye giren üst batın kesitlerinde pneumobilia saptand 1 ancak geçirilmiş ERCP'ye sekonder olduğu düşünüldü. Başlanan meropenem tedavisi ile dramatik cevap alınan hastanın kan kültürlerinde GSBL olumsuz E. coli üremesi saptanması üzerine antimiktobiyal duyarlılığına göre tedavi deeskale edilerek seftriakson tedavisine geçildi. Tedavinin 14. gününde hastada titremeyle yükselen ateşin tekrarlaması ve laboratuvar bulgularında reenfeksiyon şüphesi (CRP: 103 mg/dl, Beyaz küre: $18000 \mathrm{u} / \mathrm{L}$ ve \%88 nötrofil hakimiyeti) olması üzerine hastadan abdomen ultrasonografi ve bilgisayarlı tomografi istendi. Kliniği açıklayacak patoloji saptanamadi. Ancak tomografi görüntülerinde intrahepatik safra yollarında hava imajları fark edildi (Resim 1).

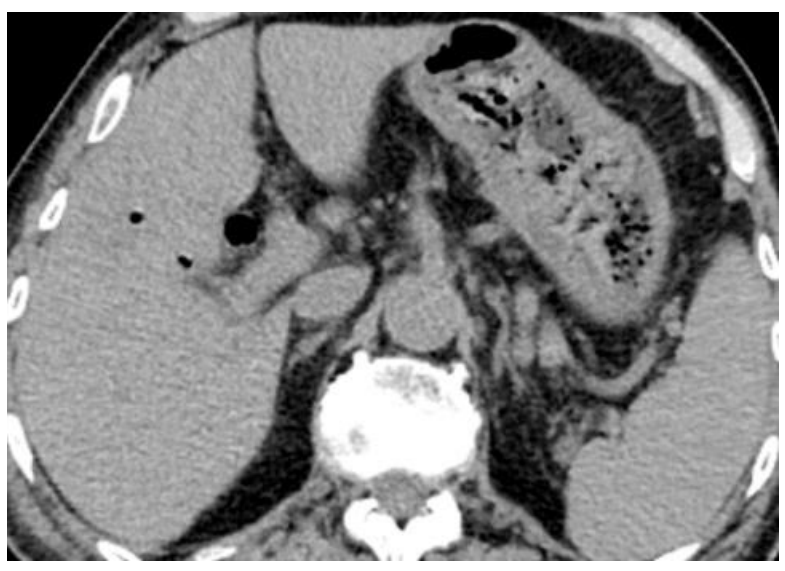

Resim 1: Abdominal Tomografide görülen intrahepatik kanallardaki hava imajları

Antibiyoterapinin 21. gününde çekilen intravenöz kontrastlı abdomen magnetik rezonans görüntüleme sonucunda safra kesesi sınırlarının düzensiz olması, 
kese içerisinde kolonla benzer hava imaj1, kese çevresinde inflame alan oluşu ve hastanın kliniği ile Mirizzi sendromu ön tanısı konuldu. Resim 2'de ana hepatik kanal ve koledokta hava, Resim 3'te kese duvarı düzensizliği, kese ve koledok içerisindeki hava görüntüsü ve muhtemel fistül alanı görülmektedir. Hasta laporoskopik işlem için cerrahiye devredildi. Hastaya yapılan laporoskopik cerrahi sonrası tip 2 Mirrizi sendromu tanısı konuldu. Geriye dönük yapılan incelemede tomografide kontrastsız çekildiği için içinde hava imajı olması nedeniyle kolon ile karışan safra kesesi ve muhtemel fistül hattı Resim 4'te gösterilmiştir.

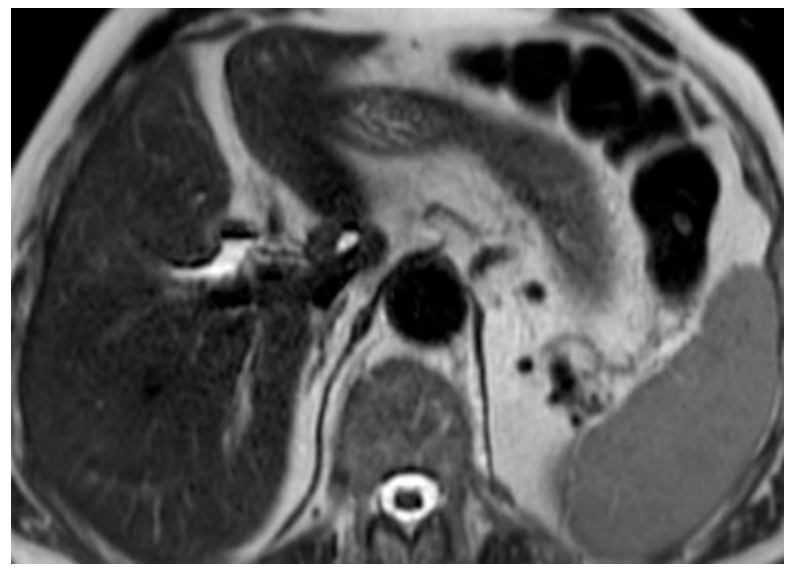

Resim 2: Abdominal MR'da görülen ana hepatik kanal ve koledokta hava imaj1

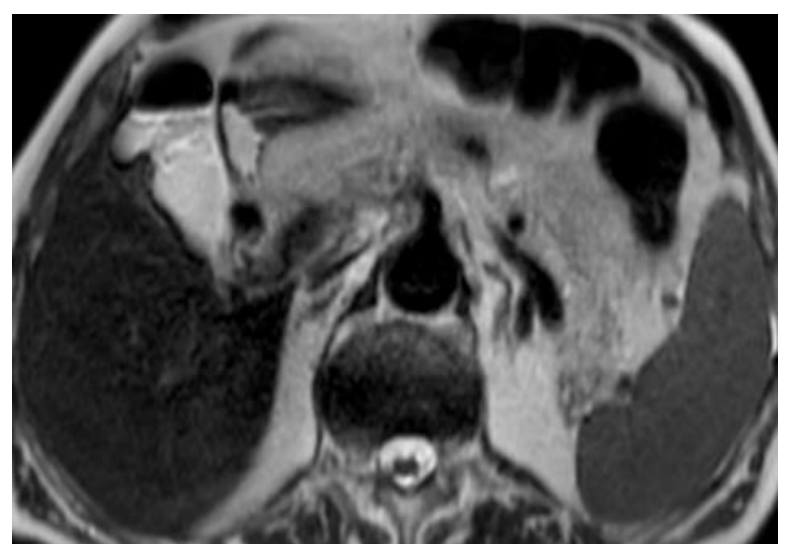

Resim 3: Abdominal MR'da görülen kese duvar düzensizliği, kese içerisinde hava, koledokta hava imaj1 ve muhtemel fistül alanı

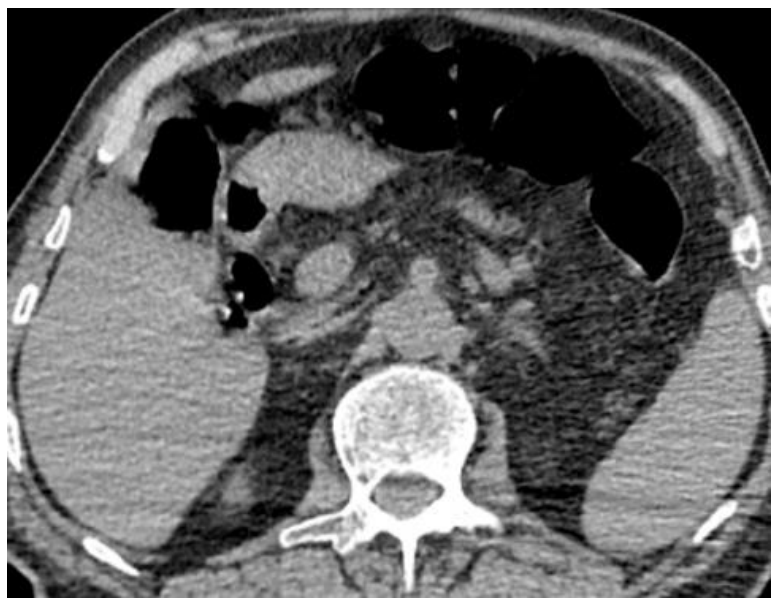

Resim 4: Abdominal BT'de görülen safra kesesi

\section{TARTIŞMA}

MS 1948 yılında tanımlanan ve günümüzde 5 alt tip için ayrı tedavi seçeneği olan bir sendromdur. Akut kolesistit ile başlayan tabloda hepatik kanala bası sonucu tip $1 \mathrm{MS}$ gelişir. Süreç kronikleştikçe safra kanalının aşınmasına bağlı olarak diğer tipler oluşur (5). MS'nun ayırıcı tanısında safra kesesi kanseri, kolanjiokarsinom, pankreas kanseri, sklerozan kolanjit veya metastatik hastalık gibi tıkanma sarılığı yapan nedenler düşünülmelidir $(7,8)$. Bizim olgumuzda ise daha önce geçirdiği ERCP sonrası koledok ile duedenum arasına stent koyulmuş olması nedeniyle tıkanma sarılığı görülmemiştir.

Cerrahi öncesi tanı koyulması zordur. Özellikle ilk görüntüleme yöntemi olan ultrasonografide MS varlığ için patognomonik bulgu olmaması gözden kaçmasına sebep olabilir (9). Bizim olgumuzda da ultrasonografide safra çamuru görülmüştü ancak MS yönünden tanı koymaya yardımcı olmadi. Toraks tomografisinde de görülen pnömobilianın ERCP sonrasıda görülebiliyor olması sebebiyle ayırıc1 tanı yapılamad1. Ancak tomografi neoplastik lezyonları, lenfadenopatileri, hepatik infiltrasyonları ekarte edebildi (10). Magnetik rezonans görüntülemenin de MS tanısına yönlendirmesi açısından ERCP kadar başarılı sonuç verdiği bilinmektedir $(1,11)$. Olgumuzda çekilen kontrastlı magnetik rezonans görüntüleme sonucunda kese 
içindeki hava imajı ile birlikte kese duvarının düzensizliği, çevre dokularda inflamasyona bağlı kirlenmelerin görülmesi sonucu hastada MS tanısı düşünülmüştür.

MS tedavisi cerrahidir. Fistül varlığına göre tamamen veya k1smen yapılacak olan kolesistektomi ile tedavi edilir (12). Bizim hastamızda da antibiyotik tedavisi kliniğgin ve laboratuvar bulgularının düzelmesini sağlamış ancak küratif etkisi olmamıştır. Cerrahi sonrası hasta kür sağlamıştır.

Akut kolesistit ve ERCP hikayesi olan hastalarda tekrarlayan ve açıklanamayan ateş gelişmesi durumunda nadir görülen komplikasyonların da ayırıcı tanıya eklenmesi hastaların tanı ve tedavi yaklaşımında yol gösterici olmaktadır.

Çatışma Beyanı: Bu çalışma sırasında, herhangi bir ilaç, tıbbi alet, gereç ve malzeme sağlayan ve/veya üreten bir firma ile herhamgi bir ticari firmadan maddi ve/veya manevi herhangi bir destek alınmamıştır.

Araştırmacıların Katkı Oranı Beyanı: Planlaması, analizi ve yazımı Ayşegül Tunaya ait olan bu çalışmanın ana fikri, verilerin sağlanması, gözden geçirme ve düzeltmelerin yapılması Canver Önal ve Okan Çalışkan tarafından yapılmış olup, herhangi bir çıkar çatışması bulunmamaktadır.

Bilgilendirilmiş Gönüllü Olur/Onam Formu: Alınmıştır.

\section{KAYNAKLAR}

1. Safioleas M, Stamatakos M, Safioleas P, Smyrnis A, Revenas C, Safioleas C. Mirizzi Syndrome: an unexpected problem of cholelithiasis. Out experience with 27 cases. Int Semin Surg Oncol. 2008;5:12-17.

2. Alberti-Flor JJ, Iskandarani M, Jeffers L, Schiff ER. Mirizzi syndrome. Am J Gastroenterol. $1985 ; 80(10): 822-3$.
3. Ölmez A, Doğan R, Aydın C, Pişkin T, Kayaalp C. Mirizzi Sendromu Tip 2: Olgu Sunumu. Dicle Tip Dergisi. 2009;36 (4):314-5.

4. Beltran MA, Csendes A, Cruces KS. The relationship of Mirizzi syndrome and cholecystoenteric fistula: validation of a modified classification. World J Surg. 2008;32(10):2237-43.

5. Csendes A, Díaz JC, Burdiles P, Maluenda F, Nava O. Mirizzi syndrome and cholecystobiliary fistula: a unifying classification. $\mathrm{Br} \quad \mathrm{J}$ Surg. 1989;76(11):1139-43.

6. Pemberton M, Wells AD. The Mirizzi Syndrome. Postgrad Med J. 1997;73(862):487-90

7. Beltran MA. Mirizzi syndrome: history, current knowledge and proposal of a simplified classification. World J Gastroenterol. 2012;18(34):4639-50.

8. Lai EC, Lau WY. Mirizzi syndrome: history, present and future development. ANZ J Surg. 2006;76(4):251-7.

9. Becker CD, Hassler H, Terrier F. Preoperative diagnosis of the Mirizzi syndrome: limitations of sonography and computed tomography. AJR. 1984;143(3):591-6.

10. Reverdito R, Moricz AD, Campos TD, Pacheco AMJ, Silva RA. Mirizzi syndrome grades III and IV: surgical treatment. Rev Col Bras Cir. 2016;43(4):243-7.

11. Chen H, Siwo EA, Khu M, Tian Y. Current trends in the management of Mirizzi Syndrome: A review of literature. Medicine (Baltimore). 2018;97(4):e9691.

12. Baer HU, Matthews JB, Schweizer WP, Gertsch P, Blumgart LH. Management of the Mirizzi syndrome and the surgical implications of cholecystcholedochal fistula. Br J Surg. 1990; 77:743-5. 